W.-D. CHU, L. ZHANG, Z. ZHANG, Q. ZHOU, F. MO, Y. ZHANG, J. WANG* (PEKING

UNIVERSITY, BEIJING AND STATE KEY LABORATORY OF ORGANOMETALLIC CHEMISTRY, SHANGHAI, P. R. OF CHINA)

Enantioselective Synthesis of Trisubstituted Allenes via Cu(I)-Catalyzed Coupling of Diazoalkanes with Terminal Alkynes

J. Am. Chem. Soc. 2016, 138, 14558-14561.

\title{
Enantioselective Coupling of Diazoalkanes with Terminal Alkynes
}

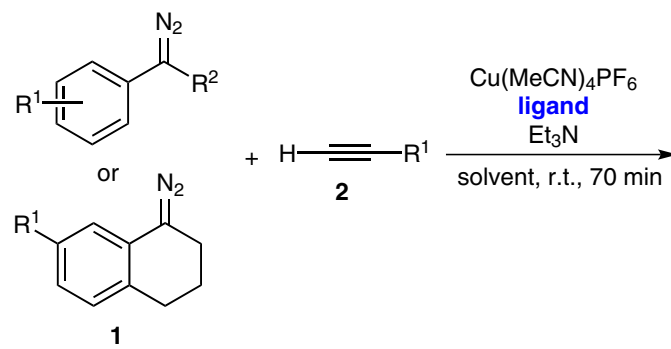<smiles>C(=C/C=C/c1ccccc1)\C=C\Cc1ccccc1</smiles>
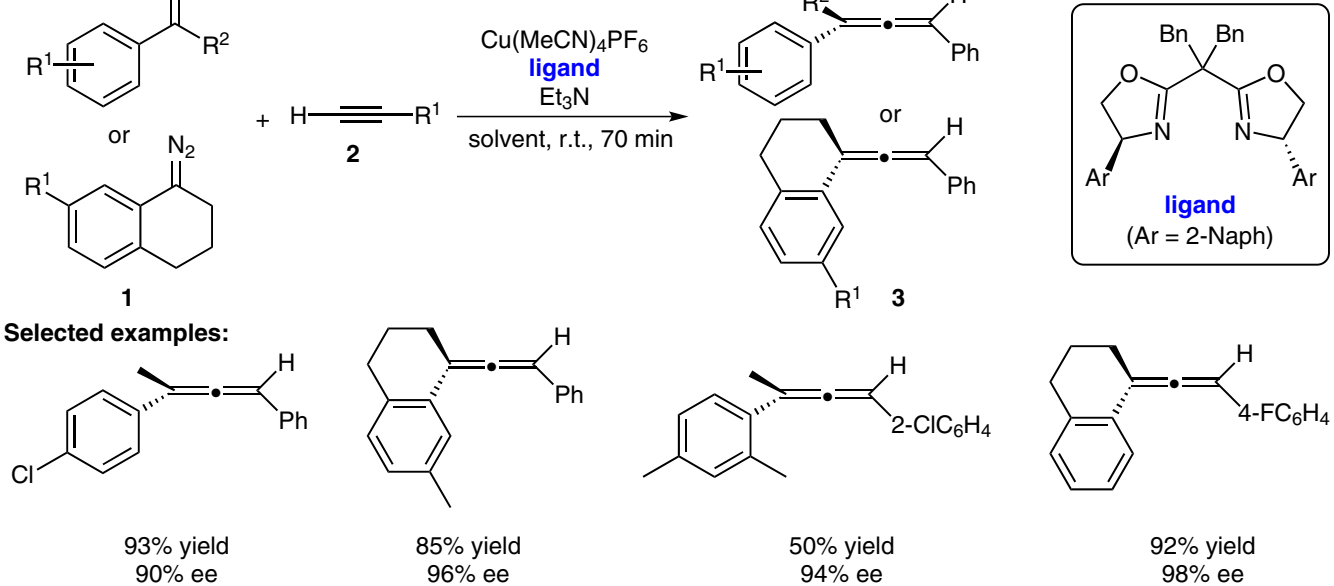

(conditions A)

\section{conditions A:}

1 (2 equiv), 2 (1 equiv)

$\mathrm{Cu}(10 \mathrm{~mol} \%)$, ligand (11 mol\%)

$\mathrm{Et}_{3} \mathrm{~N}$ (1 equiv) in $\mathrm{CH}_{2} \mathrm{Cl}_{2}-\mathrm{CHCl}_{3}(1: 1)$

conditions $\mathrm{B}$ :

1 (2 equiv), 2 (1 equiv)

$\mathrm{Cu}(20 \mathrm{~mol} \%)$, ligand (22 $\mathrm{mol} \%)$

$\mathrm{Et}_{3} \mathrm{~N}$ (1 equiv) in $\mathrm{CHCl}_{3}$
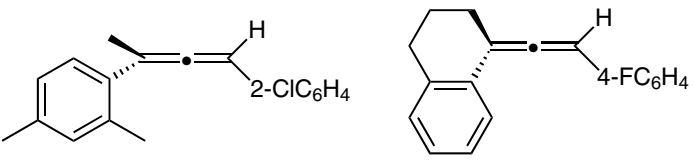

Possible stereocontrol model:
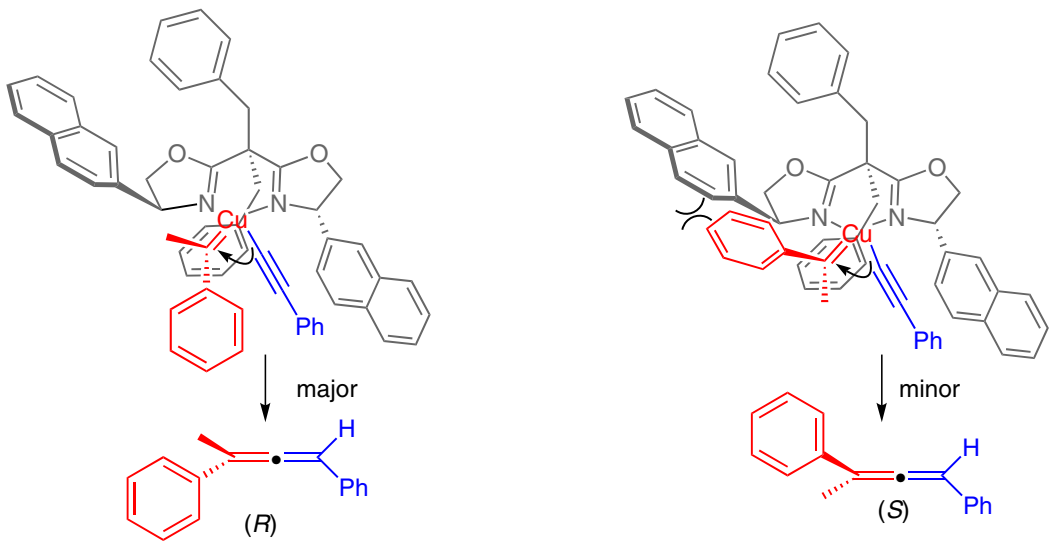

Significance: An enantioselective coupling reaction of aryldiazoalkanes with terminal alkynes is described. A copper complex promotes this transformation to afford trisubstituted allenes with high enantioselectivities. A rational stereocontrol model is proposed.

SYNFACTS Contributors: Hisashi Yamamoto, Yasushi Shimoda Synfacts 2017, 13(02), 0159 Published online: 18.01.2017 Dol: 10.1055/s-0036-1589876; Reg-No.: H16716SF

\section{Category}

Metal-Catalyzed Asymmetric

Synthesis and

Stereoselective

Reactions

\section{Key words}

copper

allenes

diazoalkenes

alkynes

enantioselective

coupling



Comment: This reaction involves copper(l) carbene formation, alkynyl migratory insertion, and protonation. The authors suggest that migratory insertion of the copper(l) carbene species is the enantiodetermining step. 